\title{
Artigo
}

\section{Identidade europeia e integração regional: Modelo de análise tridimensional das percepções identitórias na União Europeia}

European identity and regional integration: Three-dimensional analysis model of identitarian perceptions in the European Union

DOI: 10.5752/P.1809-6182.2017v14.n1.p54

Angélica Saraiva Szucko ${ }^{1}$

Recebido em: 06 de setembro de 2016 Aprovado em: 14 de janeiro de 2017

\section{RESUMO}

Este artigo faz uma investigação sobre a relação entre identidade europeia e integração regional. Tendo-se admitido a existência de uma identidade europeia fundada nas dimensóes cívico-institucional, histórico-cultural e nacional, este trabalho propóe uma análise tridimensional das percepçóes identitárias nacionais dos Estados membros da Uniäo Europeia e um modelo de distribuição espacial.

Palavras-chave: Identidade Europeia. União Europeia. Integração regional

\section{ABSTRACT}

This article presents a research on the relationship between European identity and regional integration. Considering the existence of a European identity based on civic-institutional, historic-cultural and national dimensions, this paper proposes a three-dimensional analysis of the European Union Member States' national identity perceptions.

Keywords: European identity. European Union. Regional integration

1. Doutoranda em Relaçôes Internacionais na Universidade de Brasília e professora substituta na Universidade Federal de Goiás. Mestre em Relaçôes Internacionais pela Universidade de Brasília. ORCID: 0000-0002-8589-7827 


\section{Introdução}

A integração europeia está fundada tanto em um processo de consolidação institucional como na formação de uma comunidade supranacional com valores compartilhados (CHECKEL; KATZENSTEIN, 2009; FUCHS; KLINGEMANN, 2011). Sáo esses motivos que a diferenciam dos demais processos de integraçáo regional e que despertam crescente interesse por suas singularidades e pelos avanços na cooperação interestatal.

Esse processo de integração traz também diversos desafios internos para sua consolidação, e a construção de uma identidade compartilhada é fundamental como elemento legitimador do aprofundamento das relaçóes europeias, ao mesmo tempo em que é elaborada e reforçada paulatinamente pelos próprios avanços da integraçấo. Isto decorre do fato de que a vontade política de ceder competências para o bloco ou compartilhá-las com ele, caso encontre respaldo na opinião popular doméstica majoritária, está intrinsecamente relacionada à existência de alguma identificação que os indivíduos, singular e coletivamente, tenham em relação à União Europeia.

Ademais, a solidez desta identidade coletiva está fundada nas crenças quanto à eficiência do bloco em promover os próprios interesses nacionais dos envolvidos, por meio da consolidação dos processos institucionais da União Europeia. Nesse sentido, é válido ressaltar que não se propugna necessariamente uma priorização da identidade europeia sobre a nacional, mas que ambas podem e devem coexistir harmonicamente.

De maneira geral, este estudo tem o intuito de realizar uma reflexão sobre o processo de integração regional e sobre a constituiçáo de uma identidade europeia respondendo aos seguintes questionamentos: como o processo de integração regional influencia a formaçấo da identidade europeia? E ainda, como se caracterizam as percepçôes nacionais sobre o sentimento de pertencimento à União Europeia? Desta forma, pretende-se pesquisar quais elementos, durante o processo de construçáo de uma comunidade europeia integrada e cooperativa, contribuíram para a construção de uma identidade compartilhada.

A hipótese central do estudo é a de que o processo de integração regional, principalmente por meio das instituiçôes, no curto prazo, e dos elementos histórico-culturais e nacionais, paralelamente, contribui para o fortalecimento do sentimento de europeidade nas populaçóes de seus Estados membros, assim como este reforça o apoio ao aprofundamento da integração. De modo a comprovar esta hipótese, a pesquisa utiliza-se de ferramentas quantitativas, a exemplo da base de dados estatísticos do Eurobarometer, a partir de uma perspectiva bottom-up.

Sendo assim, este artigo divide-se em três partes. Primeiramente, são expostas as bases para elaboração do desenho de pesquisa de análise tridimensional, bem como as três variáveis deste estudo - a identidade cívico-institucional, a identidade histórico-cultural e a identidade nacional. Em seguida, é elaborado o modelo de distribuição espacial denominado "cubo identitário europeu" e são elencadas suas características. Posteriormente, são apresentados os resultados gerais das percepções nacionais sobre a identidade europeia.

\section{O modelo de análise tridimensional}

O estudo da questão identitária e a avaliaçáo do sentimento de pertencimento a um ethos europeu são essenciais para entender os rumos do processo de integração no que se refere ao maior aprofundamento e ao maior alargamento do bloco. Isto porque "o grau em que um senso de identidade coletiva é necessário depende do grau de integração europeia. Um baixo grau de integração europeia 
exigiria uma fraca identidade europeia e vice-versa ${ }^{2 \text { " }}$ (FUCHS; KLINGEMANN, 2011, p. 36, tradução nossa).

Nesse sentido, é possível apontar dois fatores, um relacionado à definição dos limites do bloco e outro à legitimidade do mesmo, que ressaltam a pertinência da temática da identidade europeia no momento atual. O primeiro refere-se a uma questâo de viés ontológico sobre o processo de integração europeu, isto é, o que é a Uniāo Europeia, quais são os critérios para adentrar o bloco e até onde é possível estendê-lo. Essa resposta pode ser encontrada nos critérios de Copenhague, que definem as condiçôes necessárias para adesão de um novo membro à Uniāo Europeia.

$\mathrm{O}$ segundo fator diz respeito à legitimidade e ao suporte ao funcionamento do bloco, pois, conforme já evidenciado em pesquisas, quanto mais os cidadãos se identificam com a União Europeia, mais tendem a apoiar suas decisóes (RISSE, 2003). Em outras palavras, trata-se do problema do "déficit democrático", conceito cunhado por David Marquand, em 1979. A ausência de um demos europeu tende a distanciar a população das decisóes tomadas dentro das instituições europeias, gerando tensôes internas ao processo de integração. $\mathrm{O}$ estudo da questão identitária procura observar justamente essa relação de identificação dos cidadãos da União Europeia com o bloco e permite analisar quais fatores contribuem para o aumento da legitimidade e da confiança no processo de integração.

Ainda em relação à temática da identidade europeia, existem duas perspectivas diferentes que têm sido utilizadas pela literatura. A primeira, definida como top-down, procura definir os limites do que é "ser" europeu e concentra-se nas questóes sobre "quem" deveria ser considerado europeu e o

2. "the degree to which a sense of collective identity is necessary depends on the degree of European integration. A low degree of European integration would require a weak European identity and vice versa" que os une em termos de geografia, de valores e de herança cultural. A segunda, conhecida como bottom-up, adota uma abordagem focada nas questôes comportamentais dos cidadãos da Uniáo Europeia de maneira a responder a questionamentos sobre em que medida estes se identificam ou não com o bloco e por quais razóes o fazem (BRUTER, 2005).

A pesquisa é conduzida, neste trabalho, procurando viabilizar, de maneira empírica, mediante a análise de pesquisas de opiniáo do Eurobarometer, o estudo da identidade europeia por meio de indicadores analíticos e com respaldo na literatura consolidada sobre o tema. Nesse sentido, distancia-se de abordagens normativas, a exemplo da teoria do patriotismo constitucional de Jürgen Habermas ${ }^{3}$, que procuram definir o que deveria ser a identidade europeia pela via top-down e ressalta a perspectiva empírica que consiste em perguntar aos próprios membros da coletividade europeia em que medida estes se identificam como europeus e o que significa ser europeu para eles.

Este artigo oferece uma definiçáo operacional e comparativa da identidade europeia assentada em três variáveis fundamentais. Essas três variáveis independentes constituem três dimensões identitárias relevantes para a construção das identidades europeias: a cívico-institucional, a histórico-cultural e a nacional. As percepções das identidades europeias podem ser mais fortes ou mais fracas a depender destas três dimensões.

\section{A identidade cívico-institucional}

Em relação à dimensão cívico-institucional, atribui-se à ideia, largamente difundida na literatura sobre o tema (RISSE, 2002, 2005; CHECKEL;

3. Habermas sugere uma fase de desenvolvimento moral das sociedades caracterizada por uma identidade coletiva funda$\mathrm{da}$ em princípios universalistas. $\mathrm{O}$ patriotismo constitucional (Verfassungspatriotismus) pressupóe a aceitação de princípios liberais e democráticos e de procedimentos constitucionalmente definidos. Para mais informaçóes ver: (DA SILVA, 2004); (HABERMAS, 2003). 
KATZENSTEIN, 2009; FUCHS; KLINGEMANN, 2011), de que o processo de institucionalização contribui para o fortalecimento das identidades europeias ao moldar padróes e comportamentos e ao inserir-se no dia a dia da populaçáo, criando novas memórias coletivas compartilhadas. Em outras palavras, a identidade cívico-institucional fundamenta-se na consolidação das instituições do bloco e nas normas comunitárias.

Essa identidade é fruto da interação e do aprofundamento das relaçóes em múltiplas áreas ocorridos durante o processo de integração regional. Inicialmente o objetivo primordial das comunidades europeias era a integração das indústrias de carvão e de aço e a cooperação econômica e energética nuclear dos países participantes, e não uma união política intergovernamental ou supranacional que dela decorreu em uma lógica de transbordamento. Conforme o processo de integração foi aprofundando-se, valores e objetivos comuns, como mencionado acima, passaram a ser partilhados e serviram de base para a construção de uma narrativa sobre o que é ser europeu.

É importante ressaltar que essa identidade cívico-institucional se relaciona, sobretudo, com a existência de uma estrutura política e de símbolos compartilhados, como uma bandeira, um hino, uma moeda e a noçâo de cidadania. Quanto maior o grau de percepção das semelhanças entre os membros do bloco e mais positiva a avaliaçáo destas similaridades, mais forte é o sentimento de europeidade (FUCHS; KLINGEMANN, 2011).

\section{A identidade histórico-cultural}

No que se refere à dimensão histórico-cultural, compreende-se que a existência de um passado comum compartilhado fornece uma memória coletiva, por exemplo, por meio de símbolos ou de valores, o que adensa o sentimento de pertencimento a uma nação ou a uma comunidade imagina- da europeia. Nesse sentido, os aspectos históricos e culturais também são relevantes no processo de construção da identidade europeia, uma vez que são responsáveis por forjar as memórias compartilhadas, como as lembranças de guerras devastadoras no continente. Em oposição a esse passado nefasto, as comunidades europeias pautaram-se pela consolidação dos valores comuns que pudessem mitigar a emergência de conflitos, a exemplo da defesa da paz, da promoçáo da democracia e do Estado de direito e do respeito aos direitos humanos.

Em síntese, o sentimento de europeidade também está baseado nas experiências regionais e na memória política dos cidadãos, e, por esta razão, é importante considerar os aspectos histórico-culturais no estudo das identidades europeias. Louis Menand destaca: "a Europa foi capaz de se reconstruir política e economicamente somente esquecendo o passado; todavia, foi capaz de se definir moral e culturalmente apenas lembrando-o " " (MENAND, 2005, p. 168 apud CHECKEL; KATZENSTEIN, 2009 , p. 127 , tradução nossa). Sendo assim, quanto maior o grau de subjetividade atribuído à coletividade europeia e mais forte a conexão afetiva com os países membros do bloco, mais enraizado é o sentimento de identidade europeia (FUCHS; KLINGEMANN, 2011).

\section{A identidade nacional}

Sobre a dimensão nacional, a literatura (SCHLENKER-FISCHER, 2010; FUCHS; KLINGEMANN, 2011) aponta que o alto grau de nacionalismo, o qual emerge de uma história compartilhada e está fortemente fundado na experiência comum, é percebido como um dos principais obstáculos para a emergência de uma identidade coletiva pós-nacional europeia. A identidade

4. "Europe was able to rebuild itself politically and economically only by forgetting the past, but it was able to define itself morally and culturally only by remembering it" 
nacional, em geral, está em constante tensão com o sentimento de pertencimento a uma identidade comunitária supranacional, ainda que ambas possam coexistir harmonicamente. As ondas de resistência e de incredulidade no projeto de integração regional revelam a fragilidade da identidade europeia. Isto pode ser observado no euroceticismo de determinados países membros em momentos de questionamento do processo integrador ou na emergência de movimentos ultranacionalistas em situaçóes de crise, como evidenciado nos anos 1970 e desde a crise financeira global de 2008 e seus impactos sobre a economia do continente, ou ainda com o recente aumento no fluxo de refugiados para a Europa. Em situações como essas, o comportamento reiterado dos Estados tem sido a tentativa de responder às adversidades próprias ou sistêmicas recorrendo a soluções mais individuais do que comunitárias, explicitando a vulnerabilidade da identidade europeia.

As identidades nacionais mais abertas a outras culturas são mais propícias a uma identificação com uma identidade europeia pós-nacional. Sendo assim, quanto maior a identificação nacional, menor a possibilidade de emergência de uma identidade europeia.

O modo nacional de enquadramento das relações 'nós-eles' com relação ao 'outro' intraestatal, a exemplo das minorias culturais ou de imigrantes, influencia potencialmente essa compatibilidade; isto é, a forma como a comunidade nacional é construída no que diz respeito à diversidade cultural dentro de um país influencia a prontidão de seus cidadãos a se identificarem com uma comunidade mais ampla caracterizada por uma alta diversidade cultural como a Europa ${ }^{5}$ (FUCHS; KLINGEMANN, 2011, p. 88, tradução nossa).

5. "The national way of framing 'us-them' relations with regard to intra-state 'other' like cultural minorities or immigrants potentially influences this compatibility; that is, the way the national community is constructed with respect to cultural diversity within a country influences citizens readiness to identify with a broader community characterized by high cultural diversity such as Europe"
A partir desses argumentos, segue abaixo uma síntese esquemática da relaçâo das dimensões identitárias com a formação da identidade europeia. Esses conceitos serão utilizados na elaboração do "cubo identitário europeu".

\begin{tabular}{ll|}
$\uparrow$ Identidade cívico-institucional & $=\uparrow$ Identidade europeia \\
$\uparrow$ Identidade histórico-cultural & $=\uparrow$ Identidade europeia \\
$\uparrow$ Identidade nacional & $=\downarrow$ Identidade europeia \\
FONTE: elaboraçáo da autora &
\end{tabular}

\section{O "cubo identitório europeu"}

Como demonstrado até esta seção, a construção da identidade europeia é influenciada por diversos fatores e pode assumir diferentes significados a depender da combinação dessas três dimensôes mencionadas. Este trabalho propõe a conjugação desses três aspectos identitários em uma análise tridimensional da identidade europeia, explicitada no formato de um cubo, onde cada uma de suas dimensões se refere a um dos aspectos identitários: o cívico institucional, o histórico-cultural e o nacional, conforme a figura abaixo:

A partir da junção das três dimensões, são formados oito vértices, nomeados de $\mathrm{A}$ até $\mathrm{H}$, que constituem oito tipos ideais das identidades europeias. A tabela abaixo resume as características desses tipos ideais.

O ponto localizado no vértice $A$ pode ser considerado o tipo ideal, em sua excelência, para a constituição de uma identidade europeia pós-nacional, pois reúne, além de um baixo nacionalismo - que permite uma maior abertura a uma identidade que ultrapasse os limites estatais -, um forte passado histórico-cultural comum - responsável por forjar densas memórias coletivas compartilhadas-, e um alto grau de institucionalização - que reitera diariamente a existência dessa comunidade eu- 
Figura 1 - O "cubo identitório europeu"

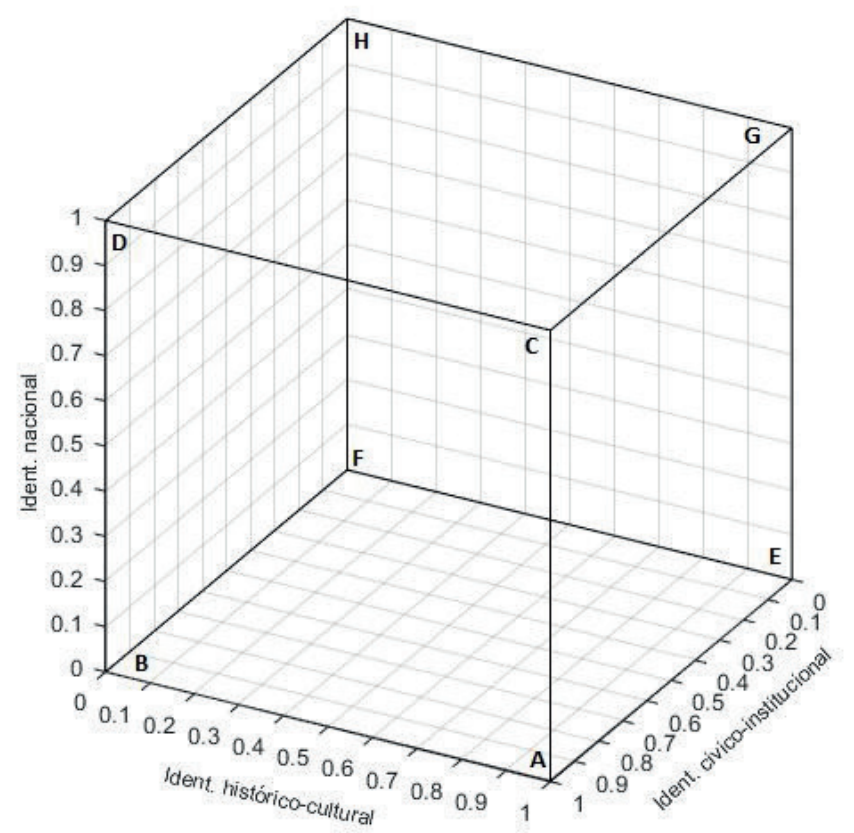

FONTE: Elaborado pela autora.

Tabela l - Características dos oito tipos ideais do "cubo identitório europeu"

\begin{tabular}{|c|c|c|c|}
\hline & IDENTIDADE NACIONAL & $\begin{array}{c}\text { IDENTIDADE HISTÓRICO } \\
\text { CULTURAL }\end{array}$ & $\begin{array}{c}\text { IDENTIDADE CÍVICO- } \\
\text { INSTITUCIONAL }\end{array}$ \\
\hline A & FRACA & FORTE & FORTE \\
\hline B & FRACA & FRACA & FORTE \\
\hline C & FORTE & FORTE & FORTE \\
\hline D & FORTE & FRACA & FORTE \\
\hline E & FRACA & FORTE & FRACA \\
\hline F & FRACA & FRACA & FRACA \\
\hline G & FORTE & FORTE & FRACA \\
\hline H & FORTE & FRACA & FRACA \\
\hline
\end{tabular}

FONTE: Elaborado pela autora

ropeia imaginada no subconsciente da população. Diametralmente oposto ao vértice $\mathrm{A}$, localiza-se o vértice $H$, que apresenta características que tendem a dificultar a emergência de uma identidade europeia pós-nacional, a exemplo do forte nacionalismo - o qual contribui para a formação de uma comunidade nacional étnica excludente-, bem como do fraco passado histórico-cultural comum e do baixo grau de institucionalização - os quais não são capazes de fomentar elementos compartilhados de uma identidade europeia.

Os pontos B e G também são diametralmente opostos. Enquanto o vértice B se caracteriza pe- las identidades nacional e histórico-cultural fracas e apresenta um alto grau de institucionalização, o $\mathrm{G}$ possui identificação nacional e passado histórico comum fortes e baixa institucionalização. Países do Leste Europeu que aderiram à Zona Euro e ao Acordo Schengen e que são mais abertos à diversidade cultural e com baixo grau de nacionalismo tenderiam a se aproximar do ponto $B$, ao passo que, próximo ao ponto $G$, se localizam países que, apesar de compartilharem experiências históricas com os demais membros do bloco, não confiam nas instituiçôes da Uniấo Europeia, delas não participam ativamente e possuem um nacionalismo exarceba- 
do, como é o caso do Reino Unido. O euroceticismo britânico e a descrença nas instituiçôes do bloco são características que evidenciam a posição ocupada pelo país no "cubo identitário europeu".

$\mathrm{Na}$ mesma lógica, os vértices $\mathrm{C}$ e F opóem-se um ao outro. $\mathrm{O}$ ponto $\mathrm{C}$ apresenta todas as três dimensóes identitárias fortes, o que sinaliza que a existência de populações nacionalistas não impede, necessariamente, o aprofundamento da integração regional se outras dimensôes também se fortalecerem. Nessa situação, os valores nacionais geralmente tendem a ser compatíveis com os comunitários, e ambas as identidades sobrepõem-se, de maneira que alguns componentes da identidade nacional estão imersos na identificação europeia e vice-versa. $\mathrm{O}$ ponto $\mathrm{F}$, em oposição, possui todas as três variáveis identitárias fracas. Nesse caso, significaria que a ausência de uma identidade nacional forte e a abertura à diversidade cultural seriam os principais elementos de identificação com a União Europeia.

Os pontos D e E também são opostos nos espectros do "cubo identitário europeu". Por um lado, o vértice $\mathrm{D}$ caracteriza-se por identidades nacional e cívico-institucional fortes, ainda que a dimensão histórico-cultural seja fraca; por outro lado, o vértice E apresenta um forte passado histórico compartilhado com os membros do bloco, baixo nacionalismo e pouca institucionalizaçáo. Os países do Leste Europeu que passaram a integrar a Uniáo Europeia nos últimos processos de alargamento tendem a migrar das posiçóes aproximadas de $\mathrm{F}$ para $\mathrm{B}$ ou de $\mathrm{H}$ para $\mathrm{D}$, a depender do baixo ou alto grau de nacionalismo, respectivamente; isso porque estes países são obrigados, assim que atingem os critérios necessários, a incorporar os avanços na institucionalizaçáo do bloco de acordo com o acquis communautaire. Em outras palavras, significa que, mais cedo ou mais tarde, estes países deverão aderir à Zona Euro e participar do Acordo Schengen.
A perspectiva construtivista entende que as identidades estão em constante transformação, e, dessa forma, os países podem mudar de posição nos espectros do cubo ao longo do tempo, principalmente em relação aos aspectos cívico-institucionais, os quais são os mais passíveis de alteraçôes no curto e no médio prazos. Esse é o caso, por exemplo, dos países que aderiram recentemente ao Euro. Ademais, vale ressaltar que os países não ocupam, necessariamente, os vértices do cubo, embora alguns se aproximem mais ou menos de um determinado tipo ideal entre os oito existentes.

\section{As percepções nacionais da identidade europeia - resultados gerais}

A proposta de uma análise tridimensional da identidade europeia permite a inclusão de diferentes variáveis que atuam sobre a construção dessas identidades, bem como a percepção dos diversos matizes das mesmas. Conforme afirmam Fuchs e Klingemann (2011), "a realidade empírica de que os cidadãos europeus carregam uma multiplicidade de identidades coloca dificuldades em termos de desenho de pesquisa, mas abre espaços para a construção de identidades cada vez mais amplas e múltiplas" (FUCHS; KLINGEMANN, 2011, p.113, tradução nossa).

Em relação às teorias sobre identidades múltiplas, o modelo do bolo marmorizado (marble cake), proposto por Thomas Risse (2003), pressupóe que alguns elementos de uma identidade coletiva podem estar imersos em outra identidade coletiva. A maior implicação desse modelo para a compreensão do caso europeu é de que a identidade europeia significa distintas coisas para pessoas diferentes, uma vez

6. "the empirical reality that European citizens espouse a multiplicity of identities poses difficulties in terms of research design, but opens spaces for the construction of ever larger and multiple identities." 
que elementos de outras identidades estáo imersos na construção das identidades europeias. A proposta do "cubo identitário europeu" busca, em certa medida, dar conta dessa complexidade, embora a análise ainda se restrinja ao plano nacional, isto é, à percepção geral dos Estados membros mediante a utilizaçáo de cross-national surveys, e não ao entendimento singular dos indivíduos; isso porque se espera, de alguma forma, explicar como essa percepçáo predominante das populaçóes nacionais tem implicaçóes nas açóes do país quanto aos avanços e aos aprofundamentos do próprio processo de integração.

Considerando os indicadores ${ }^{7}$ utilizados para medir as três variáveis - identidade cívico-institucional, identidade histórico-cultural e identidade nacional, propóe-se uma classificação dos 28 Estados membros da Uniáo Europeia no ano de 2015. A pontuação para cada item dos indicadores das três dimensões identitárias varia até três, de modo a medir, equilibradamente, todos os aspectos propostos. Ademais, o resultado final obtido para cada dimensão identitária foi ponderado em uma escala de $0 \mathrm{a}$ 1 , sendo 0 o extremo mais fraco e 1 o mais forte. A tabela 2 com os dados referentes a cada um dos itens dos indicadores e a média ponderada entre 0 e 1 do valor obtido para cada uma das dimensóes identitárias assim como o gráfico 2 ilustram os resultados.

Em relação à dimensão cívico-institucional, os principais elementos considerados foram a participação do país na Zona Euro e no Espaço Schengen no ano de 2015, bem como a atribuição do sentimento de europeidade à economia e ao Estado de Direito europeus, com base nos relatórios do Eurobarometer daquele ano. Nesse sentido, entre os países com a identidade cívico-institucional mais preeminente (igual ou acima de 0.750), destacam-se Alemanha, Espanha, Estônia e Lituânia. A Alemanha é o grande condutor do aprofundamento da institucionalização europeia e preza pelo cumprimento das normas acordadas. No caso da implementação do Euro, por exemplo, devido ao receio germânico quanto à força e à estabilidade da moeda comum quando comparado à sua moeda nacional, a Alemanha foi o principal país a insistir para que os critérios de convergência estabelecidos no Tratado de Maastricht fossem rigidamente cumpridos (RISSE, 2002).

Estônia e Lituânia, que aderiram ao Euro, respectivamente, em 2011 e 2015, também apresentaram alto grau de institucionalizaçáo, o qual, possivelmente, está relacionado tanto às mudanças pelas quais os países passaram para adotar a moeda comum, quanto às expectativas em torno da entrada na Zona Euro. A Letônia, que ingressou na Zona Euro em 2014, também apresentou um nível considerável (0.500) de identidade cívico-institucional, ainda que abaixo dos demais países bálticos.

Ao contrário, os países com os menores índices de identidade cívico-institucional (igual ou abaixo de 0.250 ), a saber, Bulgária, Croácia, Dinamarca, Reino Unido, República Tcheca, Romênia e Suécia, estão todos fora da Zona Euro. À exceção do Reino Unido e da Dinamarca, que acordaram uma opção de exclusão no Tratado de Maastricht, o qual determinou as bases para a Uniâo Econômica e Monetária (UEM), dispensando-os da participação na Zona Euro, todos os demais Estados membros da União Europeia são legalmente obrigados a aderir à moeda comum assim que sejam atendidos os critérios de convergência. A Suécia tem contornado essa exigência mediante o não cumprimento dos critérios mencionados. Para os demais países, que entraram no bloco após o estabelecimento da UEM, aplica-se o critério de Copenhague referente ao acervo comunitário.

De maneira semelhante, quatro desses países com baixa identidade cívico-institucional, Bulgária, Croácia, Reino Unido e Romênia, estão fora do Espaço Schengen. O Reino Unido, assim como a Irlanda, mantém a opção de exclusão, enquanto os 
Tabela 2 - Resultados dos indicadores das dimensões identitớrias

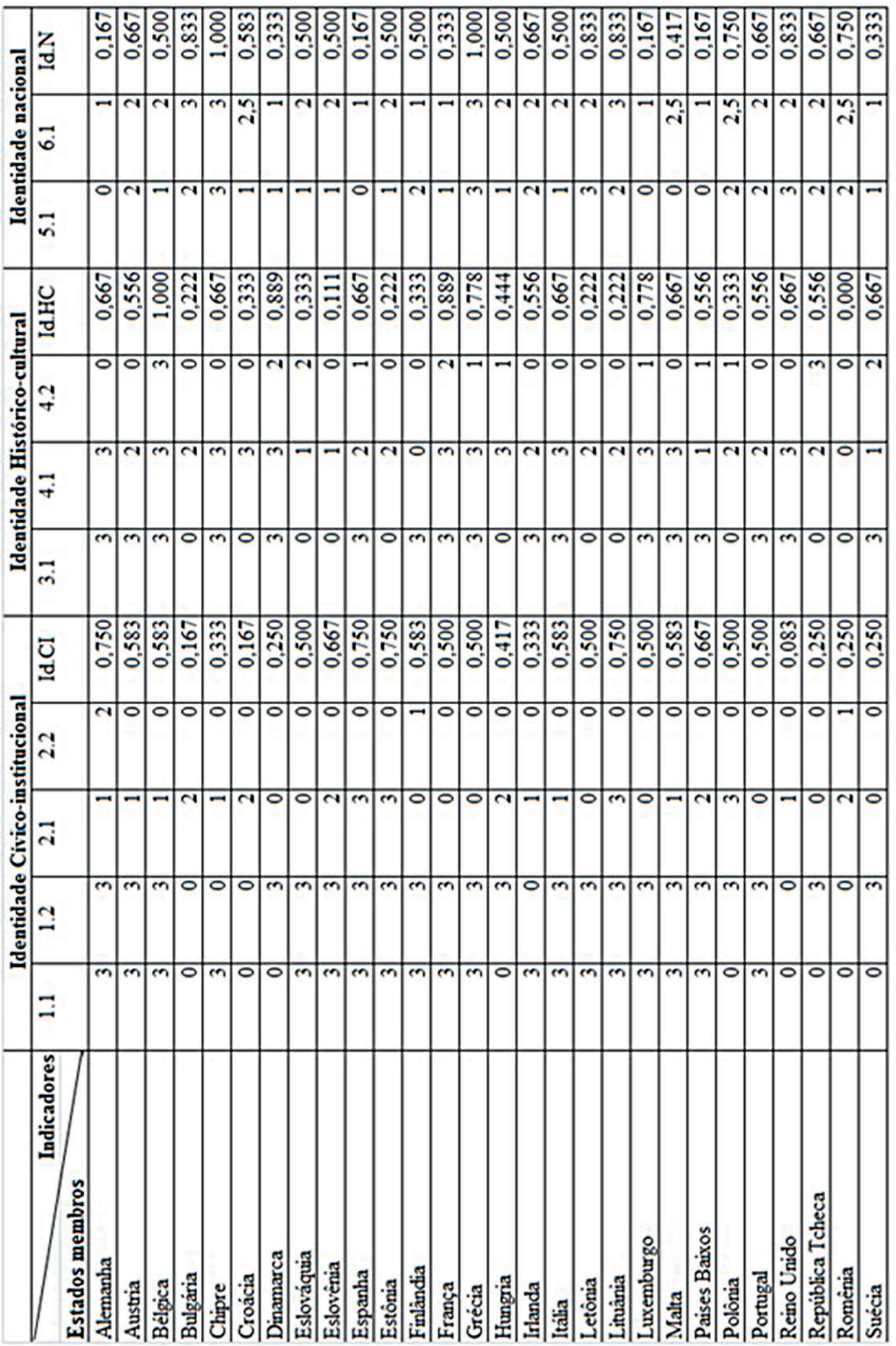


Gráfico 2 - Resultados das dimensões identitớrias dos Estados membros da Uniỡo Europeia

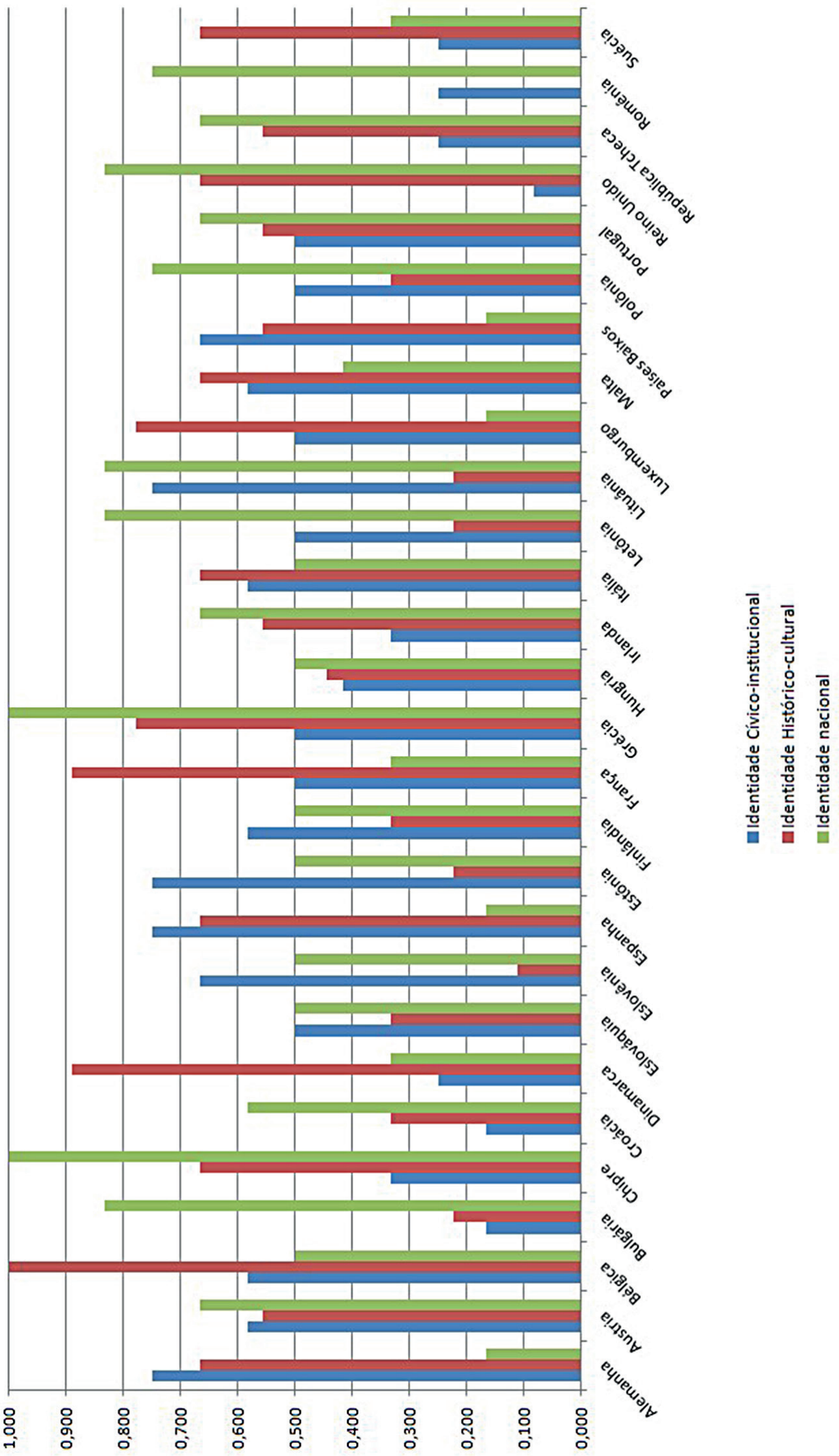


demais devem aderir ao acordo de livre circulação, conforme determinado pelo Tratado de Amsterdâ, que o incorporou à legislação do bloco.

No que diz respeito à dimensão histórico-cultural, a vinculação com regimes autoritários comunistas durante a Guerra Fria, por meio seja da Uniāo Soviética seja dos próprios governos nacionais ${ }^{8}$, foi um dos indicadores utilizados, pois simboliza um afastamento da formação ocidental europeia de tradição democrática desde o final da Segunda Guerra Mundial. Outro critério adotado para mensurar esta dimensão foi a identificação do sentimento de europeidade com a cultura e a história compartilhadas, segundo dados do Eurobarometer de 2015.

Nesta dimensão, Bélgica, Dinamarca, França, Grécia e Luxemburgo apresentaram os índices mais altos (igual ou acima de 0.750). A Grécia é considerada, em muitos casos, o berço da civilizaçáo europeia ocidental, ainda que sua formação seja permeada por diversos matizes culturais. Um dos grandes legados gregos refere-se à inspiração democrática no exemplo histórico de suas cidades-estados, principalmente de Atenas ${ }^{9}$. A França, por sua vez, disseminou, por meio dos princípios iluministas de liberdade, igualdade e fraternidade, seus valores para toda Europa Ocidental. A Revolução Francesa simbolizou um marco nas histórias europeia e mundial ao inaugurar a Idade Contemporânea e serviu de incentivo para outros países trilharem o mesmo caminho de derrubada dos regimes absolutistas e para o crescimento das repúblicas liberais democráticas.

Entre os países com a identidade histórico-cultural mais fraca (igual ou menor que 0.250 ), estão Bulgária, Eslovênia, Estônia, Letônia, Lituânia

8. No caso dos países que se formaram após a dissolução da Iugoslávia, considerou-se o governo socialista de Josip Broz Tito como um distanciamento da formação ocidental europeia no século XX.

9. Vale ressaltar que, na Grécia Antiga, a participação política estava restrita a uma pequena elite, que excluía mulheres, escravos e estrangeiros. O sufrágio universal só foi internacionalmente conquistado nos séculos XIX e XX. e Romênia. Todos esses países estiveram vinculados a regimes autoritários comunistas durante a segunda metade do século XX. De um lado, a Eslovênia integrava a República Socialista Federativa da Iugoslávia; do outro lado, Estônia, Letônia e Lituânia pertenciam à União das Repúblicas Socialistas Soviéticas. A Bulgária, entre 1946 e 1990, quando esteve sob o comando do Partido Comunista Búlgaro, era denominada República Popular da Bulgária. A Romênia ficou conhecida como República Popular da Romênia, entre 1947 e 1965 e, posteriormente, como República Socialista da Romênia, até 1989. Destarte, a aproximação com regimes comunistas os distanciava dos ideais democráticos liberais da Europa Ocidental, e estes países tiveram de passar por enormes reformas e transformaçóes internas para atenderem às condiçóes necessárias para entrada na Uniāo Europeia, em especial os critérios políticos de garantia de democracia, do Estado de Direito e de proteção aos direitos humanos, e o econômico de estabilidade do mercado. Em relação ao acervo comunitário, a maioria ainda está em processo de consolidação, uma vez que é permitido dividi-lo em diversas etapas com prazos diferentes para internalização.

Para mensurar a identidade nacional, foram utilizados tanto os resultados das pesquisas de opinião do Eurobarometer de 2015 quanto da análise empírica realizada por Andrea Schlenker-Fischer no artigo "Unity in diversity"? The acceptance of cultural diversity and its impact on the compatibility of national and European identity, apresentado em 26 de junho de 2010 no European Consortium for Political Research (ECPR) Fifth Pan-European Conference. Por este motivo, a classificaçáo dos tipos de comunidades entre étnica, cultural/republicana e cívica/liberal não incluía a Croácia naquele momento; no entanto, com base nos dados utilizados por Schlenker-Fischer (2010), foi possível classificar aproximada- 
mente o país entre comunidade étnica e cultural, com a pontuação de 2,5 para este item, à semelhança de Malta, Polônia e Romênia ${ }^{10}$.

Vale ressaltar ainda que não existem relatórios mais recentes que abrangem esses tipos de questionamento para que seja realizada uma classificação mais atual dos tipos de comunidade, conforme proposto por Schlenker-Fischer, de cada um dos Estados membros da Uniâo Europeia; contudo, é importante considerar que, embora os dados de um dos indicadores da dimensão identitária nacional sejam de 2010, e não de 2015, a identidade nacional não se altera tão drasticamente em um curto período de tempo. A identidade cívico-institucional está sujeita a um maior número de mudanças no curto e no médio prazos, enquanto as dimensóes histórico-cultural e nacional tendem a manter uma relativa estabilidade devido ao fato de estarem mais enraizadas no subconsciente e na memória coletivas das populaçóes. Por estes motivos e na ausência de dados mais atualizados em relação aos tipos de comunidade, optou-se pela utilizaçâo da classificaçáo proposta do Andrea Schlenker-Fischer (2010), com a inclusão da Croácia categorizada pela própria autora.

Os países que apresentaram um grau de nacionalismo mais proeminente (igual ou acima de 0.750 ) foram Bulgária, Chipre, Grécia, Letônia, Lituânia, Polônia, Reino Unido e Romênia. Esses países, em geral, têm mais dificuldades em aceitar a diversidade cultural, a integração dos imigrantes e/ou a constituição de identidades múltiplas, identificando-se primordialmente como "apenas nacionais" em vez de "nacionais e europeus" ou "europeus e nacionais". O Reino Unido é um grande exemplo de país que, a despeito da sociedade multicultural existente em Londres, não integra verdadeiramente os imigrantes, colocando-os como cidadáos de segunda categoria e criando guetos culturais e raciais dentro do próprio país.

10.Para maiores explicaçôes, ver a dissertação "Identidade europeia (e)levada ao cubo: um modelo de distribuiçáo espacial das percepçôes identitárias na Uniâo Europeia” de Angélica Saraiva Szucko.
Entre os países do menor grau de nacionalismo (igual ou abaixo de 0.250), estão Alemanha, Espanha, Luxemburgo e Países Baixos. O caso espanhol é peculiar para a análise da identidade nacional. É interessante notar que grande parte da população se identifica mais com a sua região, a exemplo da Catalunha, do País Basco e da Andaluzia, do que com a nação espanhola. Talvez por esse motivo a identidade nacional seja fraca no país, e a população esteja mais aberta a identificação com identidades múltiplas (ex: catalão, espanhol e europeu). Na Alemanha, a construção da identidade germânica no pós-Segunda Guerra Mundial esteve vinculada à ideia de uma Europa unida, e, por essa razão, as identidades alemã e europeia misturam-se na percepção da população. Em Luxemburgo e nos Países Baixos, ocorre um fenômeno semelhante em que a identidade nacional perde a sua força face à identidade europeia. Em resposta à pergunta "Você se identifica como..?", esses quatro países apresentam as menores porcentagens para a opção "apenas nacional" (Alemanha - 25\%; Espanha - 28\%; Luxemburgo - 17\%; Países Baixos - 26\%). Ademais, em resposta ao mesmo questionamento, Espanha (6\%) e Luxemburgo (7\%) possuem os percentuais mais elevados para a opção "apenas europeu" (EUROPEAN COMMISSION, 2015, p.22).

\section{Conclusão}

Esta pesquisa procurou realizar uma reflexão sobre a relação entre a integração regional e a formaçáo de uma identidade europeia. Pode-se concluir que o processo de integração regional, principalmente por meio das instituições, no curto prazo, e dos elementos histórico-culturais e nacionais, paralelamente, contribui para o fortalecimento do sentimento de europeidade nas populaçôes de seus Estados membros, assim como este reforça o apoio ao aprofundamento da integração. 
De modo geral, este trabalho comprova a existência de não apenas uma, mas de várias identidades europeias derivadas do processo de integração regional, bem como propóe um modelo de análise tridimensional considerando os fatores cívico-institucionais, histórico-culturais e nacionais que moldam a constituição dessas identidades. Com base nessas variáveis, é possível localizar o posicionamento de um país no "cubo identitário europeu" e a propensão à constituição de uma identidade europeia pós-nacional ou não. Este trabalho traz uma abordagem inovadora sobre a interação entre os elementos que compóem as identidades europeias e evidencia suas constantes mudanças ao longo do tempo.

O trabalho em questão aponta, ainda, que a Uniáo Europeia tem sido um ativo construtor de identidade na regiáo e que a própria associação ou mimetizaçáo do conceito de Europa (no sentido de ser um continente individualizado) com essa comunidade supranacional demonstra a importância do processo de integração na constituição de identidades. O estudo proposto, além de confirmar a identidade europeia como um resultado do processo de integração, demonstra também que o aprofundamento e a continuidade deste dependem do fortalecimento daquela identidade.

\section{Referências}

BRUTER, Michael. Citizens of Europe? The emergence of a Mass European Identity. Palgrave Macmillan: New York, 2005. CHECKEL, Jeffrey T.; KATZENSTEIN, Peter J. (ed.) European Identity. Cambridge: Cambridge University Press, 2009. COMISSÃO EUROPEIA. Compreender as políticas da Uniāo Europeia: A União Econômica e Monetária e o Euro. União Europeia, 2015.

COLLIER, Ruth B. Paths toward democracy: the working class and elites in Western Europe and South America. Cambridge: Cambridge University Press, 1999.

DA SILVA, Filipe Carreira. Cidadáos da Europa? Algumas reflexões sobre o patriotismo constitucional. In: Revista Crítica de Ciências Sociais. v.70, 2004, p. 127-145.

EUROPEAN COMMISSION. European citizenship. Standard Eurobarometer 77, Spring, May 2012.
EUROPEAN COMMISSION. European citizenship. Standard Eurobarometer 79, Spring, May 2013.

EUROPEAN COMMISSION. European citizenship. Standard Eurobarometer 81, Spring, June 2014.

EUROPEAN COMMISION. The Euro Area. Flash Eurobarometer 405, October 2014.

EUROPEAN COMMISSION. European citizenship. Standard Eurobarometer 83, Spring, May 2015.

FUCHS, Dieter ; KLINGEMANN, Hans-Dieter (eds.). Cultural Diversity, European Identity and the Legitimacy of the EU. Cheltenham, UK; Northampton, USA: Edward Elgar, 2011.

HABERMAS, Jürgen. Towards a Cosmopolitan Europe. In: Journal of Democracy. v.14, n.4, p. 86-100, 2003.

RISSE, Thomas. The Euro and Identity Politics in Europe. In: CONFERÊNCIA "THE YEAR OF THE EURO”, Nanovic Institute for European Studies, University of Notre Dame, Dec. 6-8, 2002.

RISSE, Thomas. European institutions and identity change: what have we learned? In: HERRMANN, Richard; BREWER, Marylinn, RISSE, Thomas (ed). Identities in Europe and the institutions of European Union. Lanhan MD: Rowman \& Littlefield, 2003.

RISSE, Thomas. Neo-functionalism, European Identity, and the Puzzles of European Integration. In: Journal of European Public Policy, Special Issue, 2005.

SCHLENKER-FISCHER, Andrea. Unity in diversity"? The acceptance of cultural diversity and its impact on the compatibility of national and European identity. In: ECPR FIFTH PAN-EUROPEAN CONFERENCE, University of Porto, June 26, 2010.

\section{Apêndice: indicadores}

\section{Identidade cívico-institucional (12-0)}

1. Grau de institucionalização:

1.1 Adesão à Zona Euro: Sim (3); Não (0)

1.2 Participação no Espaço Schengen: Sim (3); Não (0)

2. Sentimento de Europeidade: QD4. In your opinion, among the following issues, which are those that most create a felling of community among EU citizens?" (EUROPEAN COMMISSION, 2015, p. 28)

\subsection{Economia:}

- Primeira posição (3)

- Segunda posiçấo (2)

- Terceira posição (1) 
- Outras posições $(0)$

2.2 Leis:

- Primeira posição (3)

- Segunda posição (2)

- Terceira posição (1)

- Outras posições $(0)$

\section{Identidade histórico-cultural (9-0)}

3. Formação ocidental europeia no século XX:

3.1 Vinculação a regimes autoritários comunistas: Sim (0); Não (3)

4. Sentimento de Europeidade: QD4. In your opinion, among the following issues, which are those that most create a felling of community among EU citizens?" (EUROPEAN COMMISSION, 2015, p. 28)

4.1 Cultura:

- Primeira posição (3)

- Segunda posição (2)

- Terceira posição (1)

- Outras posiçóes (0)

4.2 História:

- Primeira posição (3)

- Segunda posição (2)

- Terceira posição (1)

- Outras posições $(0)$

\section{Identidade nacional $(6-0)$}

5. Grau de nacionalismo: QD2. Do you see yourself as...? Options: nationality only, nationality and European, European and nationality, total European"(EUROPEAN COMMISSION, 2015, p. 22)

5.1 Percentual na opção "apenas nacional”:

- 10\% ou mais acima da média europeia (3);

- Entre 1\% e 9\% acima da média europeia (2);

- Entre 0\% e 9\% abaixo da média europeia (1);

- 10\% ou mais abaixo da média europeia (0).

6. Comportamento em relação a outras culturas e a populações imigrantes:

6.1 Tipo de comunidade:

- Primordial/étnica [nacionalista] (3)
- Intermediária entre étnica e cultural11 $(2,5)$

- Tradicional/republicana/cultural [multinacional] (2)

- Universalista/liberal/cívica [pós-nacional] (1)
11. De acordo com Schlenker-Fischer (2010, p. 22): “Citizens in Romania and Poland also restrict Access to their national community quite strongly, yet, nevertheless accept cultural diversity more that ethnic countries. In contrast, the majority in Malta does not make access depend om Maltese ancestry, yet they accept least cultural diversity. Therefore, these countries do not fit into the classification proposed here." Por estes motivos, foi proposta uma classificação intermediária entre as comunidades étnicas e culturais. 